\title{
La nada como ejercicio creador. La Guía espiritual de Molinos en Zambrano y Valente
}

\author{
Tatiana Aguilar-Álvarez Bay
}

En este artículo se analiza la Guía espiritual de Miguel de Molinos a partir de los estudios de María Zambrano y José Ángel Valente. Se aborda el papel que en la obra de Molinos desempeña el concepto de la nada como medio para alcanzar la divinidad. También se observa la importancia de la Guía como género literario y se habla en específico de la Guía espiritual como manual de aprendizaje práctico que se opone al conocimiento puramente escolástico y persigue el autoconocimiento. Asimismo la suerte histórica que tuvo Miguel de Molinos se contrasta con la de san Juan de la Cruz.

Palabras Clave: Guía, Guía espiritual, la nada, Miguel de Molinos, María Zambrano, José Ángel Valente, mística.

In this paper Miguel de Molinos' Guía espiritual is studied from María Zambrano and José Ángel Valente's studies. The rol that the concept of nothingness has in Molinos' works as a mean of reaching the divinity and the importance of the Guía as a literary genre are also explored. The Guía espiritual is seen as a manual of practical learning that seeks self-knowledge that opposes the merely scholastic knowledge. Moreover, the Molino's historic luck is contrasted with the one that had san Juan de la Cruz.

KEYwORDS: Guía, Guía espiritual, the nothingness, Miguel de Molinos, María Zambrano, José Ángel Valente, mysticism.

Fecha de recepción: 13 de septiembre de 2013

Fecha de aceptación: 15 de enero de 2014 



\author{
Tatiana Aguilar-Álvarez Bay \\ Universidad Nacional Autónoma de México \\ Instituto de Investigaciones Filológicas
}

\title{
La nada como ejercicio creador. \\ La Guía espiritual de Molinos en Zambrano y Valente
}

Un libro ocupa el centro de este artículo. Se trata de la Guía espiritual de Miguel de Molinos (1628-1696), obra impresa por primera vez en 1675, y que circula ampliamente en su momento para caer después en el olvido. ${ }^{1}$ En nuestros días ha llamado la atención el humillante proceso de Molinos, a quien las autoridades religiosas condenan a la cárcel, donde pasa los últimos nueve años de su vida. A la vez, se vuelve la vista al registro, de sorprendente precisión y claridad, del trayecto espiritual que se encuentra en su Guía. En lo que sigue, reviso la resonancia de Molinos en dos personajes centrales de la posguerra española: María Zambrano y

${ }^{1}$ Según refiere José Ángel Valente, poco después de ser publicada, la Guía se reestampó tres veces en España y se reimprimió numerosas veces en Italia. En 1687 se publica en latín, en 1688 en francés, holandés e inglés, y en 1699 en alemán. Cfr. p. 257 de la edición del poeta, basada en la primera romana de 1675 y en una versión inédita resguardada en la Biblioteca Apostólica Vaticana. Anteriormente se había reproducido, sin mayor cuidado, la segunda edición de la Guía, impresa en Madrid en 1676. En lo que sigue cito en el cuerpo del trabajo a partir de la edición de Valente: Guía espiritual. Defensa de la contemplación, Barcelona, Barral, 1974. A manera de prólogo el poeta incluye un "Ensayo sobre Miguel de Molinos". El título Guía espiritual, va sucedido por el subtítulo: "Que desembaraza al alma y la conduce por el interior camino para alcanzar la perfecta contemplación y el rico tesoro de la interior paz". 
José Ángel Valente. Me refiero también al apasionado interés que el místico despierta en dos cubanos: Lezama Lima y Calvert Casey, y al papel que ellos juegan en el descubrimiento de la Guía por parte de Valente.

La Guía espiritual se dirige a un público interesado más en la mística que en los estudios teológicos. En la línea de san Juan de la Cruz, Molinos escribe con un propósito eminentemente práctico; pone su propia experiencia a disposición de un grupo que intenta ir más allá de formas religiosas convencionales, lo que en su vocabulario se describe como tránsito de la "meditación" a la "contemplación". ${ }^{2}$ Este libro debe verse entonces como "manual", en el sentido de conjunto de enseñanzas de un maestro dedicado y generoso que busca facilitar el aprendizaje de sus alumnos. Se trata de un libro de cabecera, de lectura salteada, con pasajes marcados a los que se vuelve y que está a la mano para dar ánimo, acompañar y resolver dudas. El estilo llano, terso, de la Guía corresponde a esta necesidad de entrar en contacto con un lector necesitado de consejo y que, muy probablemente, ha acudido antes a otros maestros o directores espirituales sin obtener resultados. En su estudio sobre la "Guía" en tanto que género literario, María Zambrano afirma incluso que ésta es comparable con la carta, escrita exclusivamente en función del destinatario. ${ }^{3}$ El pensamiento de Molinos, marcado por la práctica, escapa a la interpretación meramente doctrinal; la experiencia que él comunica, individual, irreemplazable, no se puede clasificar dentro de tal o cual compendio de ideas. En pocas palabras, Molinos no escribe para estudiosos, sino para los interesados en el autoconocimiento, de ahí la afinidad que despierta en Zambrano y Valente.

De forma general, Molinos se adscribe al quietismo, corriente espiritual que procede de la mística flamenca basada en la teología negativa, concretamente de los begardos del siglo xIV, y de autores como Maister Eckhart y Taulero. ${ }^{4}$ Entre los escritores españoles fue Valle Inclán el

2 La oración discursiva es un camino autorizado, mientras que la contemplación, desde una perspectiva racionalista, se considera sospechosa y se proscribe. Como explica Valente, lo que se aprueba en san Juan de la Cruz, un siglo después, se condena en Molinos.

3 "La Guía está por completo polarizada al que lee, es como una carta" ("La Guía, forma del pensamiento", 158-159).

4 Sólo para contextualizar, añado información general sobre este movimiento, no sin subrayar antes la distinción, ya mencionada, entre las formulaciones a posteriori de 
primero en reivindicar la "aniquilación" molinista como meta del trayecto espiritual. ${ }^{5}$ Este proceso incluye dos vertientes. De un lado, la convivencia estrecha con la nada, y de otro, la renovación a que da lugar la "retracción" del yo - en vocabulario de Valente-. En consonancia con el vaivén paradójico de san Juan de la Cruz, es necesario vaciar para colmar - dejar para adquirir - , como se indica en el capítulo titulado "De la verdadera y perfecta aniquilación":

Sabrás que esta aniquilación [...] ha de ser en el propio juicio, en la voluntad, en los afectos, inclinaciones, deseos, pensamientos y en sí misma, de tal manera que se ha de hallar el alma muerta al querer, al desear, procurar, entender y pensar, queriendo como si no quisiera, entendiendo como si no entendiera, pensando como si no pensara, sin inclinarse a nada [...] ¡Oh, qué dichosa alma la que así se halla muerta y aniquilada! [...] ya con toda verdad se puede decir que es otra fénix renovada, porque está trocada, espiritualizada, transformada, deificada (Guía, 244). ${ }^{6}$

En consonancia con el áspero camino aquí propuesto, más que de excelsitud o de exaltación, Molinos trata de sobriedad y silencio, de ahí su extremada cautela, por ejemplo, ante los denominados "fenómenos

la corriente quietista, y la inclasificable aventura espiritual del propio Molinos. Como señala Dodin en su artículo sobre los begardos, "cuatro categorías de errores" constituyen la base común del quietismo: 1) Despreocupación respecto a las postrimerías, puesto que en ocasiones por medio de la "contemplación adquirida" se puede gozar ya en el mundo de la beatitud. 2) Al aspirar a la "deificación", niegan la distinción radical entre el hombre y Dios. 3) Una vez que se ha llegado a la cumbre espiritual, la conducta se considera indiferente, lo que da lugar a veces al desenfreno sexual. 4) Al considerar la oración interior como única verdadera, la oración vocal, los sacramentos y la piedad eucarística pierden valor. Cfr. André Dodin, Diccionario de las religiones, s.v.

${ }^{5}$ Debo al profesor José Ricardo Chaves la noticia del importante papel que desempeñan los teósofos españoles de finales del XIX en el rescate de Molinos. Los integrantes de este grupo se dan a la tarea de localizar precursores de su movimiento en España, y no sólo en Europa, de ahí el interés por Miguel de Molinos. Entre estos teósofos destaca Rafael Urbano (fallecido en 1925), traductor de Nietzsche, y colaborador de la revista Sophía.

${ }^{6}$ Las cursivas son mías. La negación no debe entenderse como odio al propio ser, sino como expansión del ser que sólo es posible cuando se supera la limitación del yo, el plano mental. Casi al final de la Guía, Molinos muestra que el ejercicio místico conduce a la felicidad. Cfr. Libro tercero, capítulo XxI, "De la suma felicidad de la interior paz, y de sus maravillosos efectos" (248-251). 
sobrenaturales", entre los que se cuenta, por ejemplo, el éxtasis. ${ }^{7}$ Esta contención permea la prosa de la Guía, cuya sencillez admira a lectores contemporáneos. ${ }^{8}$ En concordancia con el místico, para Valente la manifestación llamativa de lo espiritual puede compararse, en términos poéticos, con el gusto por lo rebuscado que va en contra de la autenticidad. El ideal de Molinos, del que Valente busca un equivalente poético, encuentra justa expresión en este pensamiento: "Donde mora el divino espíritu siempre se halla la sencillez y la santa libertad. Pero la astucia, la doblez, la ficción, el artificio, la política y mundanos respetos son infierno para los hombres sabios y sencillos" (240). Asociada con la política del Barroco, esta tendencia al espectáculo conduce al deslumbramiento por el que se distrae a la gente de los asuntos de verdadera importancia. ${ }^{9}$ El poeta retoma la actitud de Antonio Machado, directa y discretamente combativa, y también su poética de la naturalidad que se opone, de acuerdo con las enseñanzas de Juan de Mairena, a la exageración atribuida al Barroco. De ahí las reservas de Valente ante el "esteticismo" de la Generación del 27, entendido como gusto por el juego y por el alarde verbal, cuya contrapartida sería el rechazo del adorno y de la abundancia expresiva.

${ }^{7}$ La contraposición entre escolástica y sabiduría constituye una de las constantes de la Guia: "La sabiduría se gusta en las obras y palabras del sabio, porque como es señor absoluto de todas sus pasiones, movimientos y afectos, se manifiesta en todas sus obras como una quieta y agradable agua en la cual se ve lucir la sabiduría con claridad" (235). A los 18 años, en 1646, Molinos se instala en Valencia para estudiar en el Colegio de San Pablo de los jesuitas, donde se hace sacerdote y obtiene el doctorado en teología. Permanece ahí hasta 1663, cuando se traslada a Roma. El místico no rechaza la instrucción, sino la erudición que se aparta de la conducta.

${ }^{8}$ Transcribo, como muestra, un pasaje del capítulo de la Guía titulado "Del silencio interno y místico", predilecto de Lezama: "La perfección del alma no consiste en hablar ni en pensar mucho en Dios, sino en amarle mucho. Alcánzase este amor por medio de la resignación perfecta y el silencio interior. Todo es obras; el amor de Dios tiene pocas palabras. [...] porque obras son amores y no buenas razones. [...] San Pedro dijo al Señor con grande afecto que por su amor perdería muy buena gana la vida, y a una palabrita de una mozuela le negó y se acabó el fervor. [...] La Magdalena no habló palabra, y el mismo Señor, enamorado de su amor perfecto, se hizo su cronista diciendo que amó mucho" (132-133).

9 Cfr. José Ángel Valente, "Teresa 'in capella Cornaro"”, Obras Completas II. La piedra y el centro, 296-300. En adelante cito a partir de esta edición con la sigla OCI, seguida del número de página. 
Así, a fines del XIX y principios del xx, Molinos aparece como un autor "secreto". Más adelante, José Ángel Valente, con el rescate editorial de la Guía, reintroduce al místico en la discusión poética del momento, lo que constituye todo un "suceso", como señala Zambrano al saludar esta cuidada edición:

Han de ser especialmente sensibles a ese suceso quienes, como quien esto escribe, hayan hecho de la Guía de Molinos un lugar de constante referencia, de consideración indispensable para vislumbrar al menos ciertas honduras del querer y de la voluntad, de la libertad verdadera, que es al par obediencia y acuerdo total. Algo que se presenta como supremo conflicto en este pensador español — que el místico no deja de serlo- en la encrucijada decisiva del espíritu europeo ("Miguel de Molinos reaparecido", 158-159).

La filósofa argumenta aquí a favor de la mística como forma de pensamiento. Se trata de una forma de razón que se ejerce respecto a lo "impensable", es decir, frente a lo que la excede; en cambio, la razón "triunfante" sólo opera en relación con un objeto proporcional: "la mística lucha con lo indecible, el pensamiento con lo impensable, como la fe con lo increíble y el amor con la opacidad" (158-159). Paradójicamente, es necesario impulsar la razón hacia lo que parece fuera de su alcance: lo "impensable". Tal osadía constituye una constante en la tradición española. En esta línea, Molinos se sitúa en una genealogía de pensadores interesados primordialmente en la vertiente práctica del pensamiento, como Séneca, san Juan de la Cruz, Machado, Unamuno. Los teósofos del XIx y Valle Inclán están intrigados por el saber oculto que reserva el olvidado Molinos, mientras que María Zambrano y José Ángel Valente muestran la actualidad y relevancia política del proceso de este personaje. No es de extrañar este giro en un autor como Valente, para el que la atención al presente, entendida como registro seco y contundente de la injusticia, forma parte de la función poética. 
San Juan de la Cruz (1542-1591) experimentó duras persecuciones, pero al final se disiparon las sospechas que lo rodeaban, y actualmente se cuenta entre los santos del catolicismo; un siglo más tarde, como ya se vio, el también español Miguel de Molinos (1628-1696) corre una suerte muy distinta, ya que las 68 proposiciones en que se resume su doctrina son proscritas. Pero Molinos, según expliqué, lejos de haber producido laboriosamente una suma de saber, más bien pone a disposición del lector su propio itinerario espiritual.

La suerte de san Juan de la Cruz y la de Miguel de Molinos no puede ser entonces más contrastante: el primero se transforma, con todo derecho, en un clásico tanto de la espiritualidad como de la literatura; mientras que sobre la obra y figura del segundo se tiende un espeso silencio. Sin embargo, como no se cansa de argumentar el poeta José Ángel Valente en defensa de Molinos, la espiritualidad de éste es de clara filiación sanjuanista. Por ello, el poeta lamenta la indiferencia con que se recibe el tercer centenario de la muerte de "la última gran figura de la mística española" (oCII, 733).

La batalla de Valente en favor de Molinos se libra en dos frentes: la reivindicación del personaje y el rescate textual. En lo que se refiere a lo primero, opta por la evocación, tanto en verso como en prosa, del ignominioso proceso del aragonés. Parodiando el escueto estilo judicial, Valente registra el orden de los hechos; se limita a encuadrar al místico vestido con el traje amarillo de los retractados, de rodillas y con un cirio encendido entre las manos, durante una ceremonia que dura dos horas. No hace falta añadir más: la actitud de Molinos, que se mantiene impasible, de acuerdo con lo que enseña en la Guía, basta para mostrar la desmesura y arbitrariedad de sus acusadores. Profundamente impresionado por las implicaciones morales e intelectuales de este proceso, el poeta necesita regresar al lugar donde ocurrió, la basílica romana de Santa Maria sopra Minerva. Se trata de una visita ritual, como indica en el ensayo "La nada":

He escrito intensamente sobre el escenario de esa abjuración y sobre la iglesia de la Minerva, adonde vuelvo una y otra vez en Roma, porque 
allí están Catalina de Siena, el Beato Angélico, y nuestro arzobispo de Toledo fray Bartolomé Carranza, víctima, asimismo, de los rigores o las insidias inquisitoriales.

Pero vuelvo, sobre todo, para imaginar de nuevo el escenario de la retractación de Molinos (OCII, 733).

En la década de los setenta Valente publica dos libros que remiten a Molinos. Primero aparece, en Joaquín Mortiz, El inocente (1970), donde se incluye "Una oscura noticia", poema escrito como homenaje a Molinos, y posteriormente, en Barral, la Guía espiritual (1974). De este modo, la prosa de Molinos queda al alcance de un público heterogéneo. Con el objeto de mostrar la continuidad entre Molinos y san Juan de la Cruz, Valente incluye además en su edición de la Guía una selección de fragmentos inéditos de Defensa de la contemplación, donde abundan las citas del santo de las "paradojas" "para venir a serlo todo, no quieras ser algo en nada" ("La nada", 734-735). En el largo ensayo que precede a la edición, el poeta señala la necesidad de estudiar paralelamente el fenómeno místico y el lenguaje en que éste se expresa:

Cernido en un tamiz de fuego, el lenguaje del místico está radicalmente determinado por sus contenidos o por una experiencia cuyo contenido último es el vacío en cuanto negación de todo contenido que se oponga al estado de transparencia, de receptibilidad o de disponibilidad absolutas en que la experiencia mística se hace posible (12). ${ }^{10}$

Y más adelante continúa:

Abolición del discursus, ingreso del lenguaje en una salida de sí mismo, transformación de la palabra de instrumento de comunicación en forma de contemplación $[. .$.$] Hay en todos los elementos antedichos un movi-$ miento de apertura, de negación de límites, de irresistible salida (13-14).

Al rescatar a Molinos, Valente también rinde homenaje a los incontables hombres y mujeres que en el pasado reciente han sufrido un destino semejante, entre los que se cuentan, en primer plano, los exiliados espa-

${ }^{10}$ Más adelante Eulogio Pacho publica completa La defensa de la contemplación. 
ñoles contemporáneos, con quienes el poeta, que lleva fuera de España quince años, ha tenido ocasión de tratar y de los que recibe la visión de su país a la que no tuvo acceso en su infancia y juventud. Sin embargo, el gesto se extiende a otras latitudes, particularmente a Cuba, por la amistad que Valente entabla con José Lezama Lima y Calvert Casey, quienes se vinculan estrechamente, al decir del español, con el encuentro de Molinos y de su Guía. En efecto, el poemario titulado El inocente se dedica a la memoria de Calvert Casey, y recoge un homenaje a Lezama Lima, designado como "maestro". Así, se marca la continuidad entre Molinos, Lezama y Casey, en cuyo suicidio, al parecer de Valente, influyen tanto su condición homosexual como el exilio. ${ }^{11}$ Superpuestos en la evocación del poeta, estos personajes aparecen como episodios de una historia en que prevalece la injusticia, cuando no la estupidez, y de la que forma parte la serie de los "inocentes" a los que el libro quiere dar voz. Así en "Una oscura noticia", incluido también en El inocente, se cuestiona no sólo este juicio, sino la voluntad de administrar la experiencia mística que escapa, por definición, del orden institucional. ${ }^{12}$ De este poema transcribo una estrofa donde la aspiración de Molinos, el abrazo tenaz de la nada, aparece como motivo de recuerdo y admiración:

${ }^{11}$ Al respecto afirma Rafael Rojas: "Muy pronto, sin embargo, Casey y otros escritores homosexuales de su generación comprenderían que las versiones más ortodoxas de la ideología revolucionaria, lejos de atemperar el machismo y la homofobia, los recodificaban como valores afirmativos de la nueva moral socialista. A medida que avanzaba ese proceso de traducción y remolde autoritario, la obra y vida de Casey se afirmaban, con mayor firmeza, en su condición literaria, exiliada y homosexual" ("Calvert Casey. Herido por la luz", 50).

${ }^{12} \mathrm{La}$ autoridad otorgada al sujeto, a la validez de su experiencia, anticipa la modernidad. Sin embargo, como señala Albert Ribas, esta afirmación del sujeto en la mística va seguida de la disolución, por lo que se entra en contradicción con los ideales ilustrados: "Sin embargo, la experiencia y propuesta de Molinos contiene en ella misma una contradicción - propia de toda corriente mística — que la hace difícilmente asimilable por la modernidad. De un lado, se parte del sujeto individual, de la autoridad de su experiencia espiritual, pero eso es sólo un punto de partida ya que a lo que se aspira es a la disolución del sujeto en la unión mística. Esta contradicción (apelación al sujeto y disolución del mismo) es contraria a la opción moderna, caracterizada por su adhesión a uno solo de los términos de la contradicción: la autoridad del sujeto ("La mística heterodoxa de Miguel de Molinos”, 27-30). 


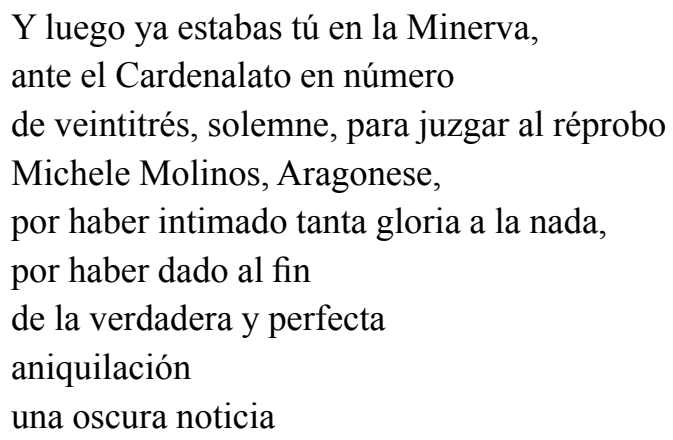

(Obras Completas I, Poesía y prosa, 316) ${ }^{13}$

Al escribir este poema, Valente ha dejado atrás su primera fase realista, y todavía no entra de lleno en la exploración formal y metafísica que define su fase final - menos ligada a circunstancias particulares-. En El inocente, especialmente en la sección que incluye "Una oscura noticia", tercera y última del libro, se nota la disminución de la fe en la poesía como agente de transformación social. En este momento Valente, además de cuestionar el alcance de la palabra poética, adopta una visión más distante de la realidad española; de forma más general, cuestiona el afán de dominio, del que sólo estaría libre, en el sentido de no ejercerlo, el inocente a que hace referencia el título del libro. De este modo, el tema político se vincula con las pesquisas de orden místico que acompañan desde sus inicios a Valente. Dicho de otro modo: la enseñanza de Molinos acerca del aniquilamiento tiene que ver con una ética de rechazo a todas las formas de control. Y esto porque al retraerse el yo, disminuye la tendencia a imponerse a los demás.

En el poema antes citado se registra la "quietud" de que hace gala Molinos durante su proceso, actitud que se ajusta al programa de la Guía que consiste en la conquista de la inmovilidad, entendida como despreocupación frente a todo lo que puede desestabilizar el ánimo: los cambios de suerte, los agravios, los vaivenes de la fama:

Y si deseas saber quién es el que totalmente es tirado al interior retiro con alumbrada simplificación en Dios, digo que es aquel que en la adversi-

${ }^{13}$ Cito a partir de esta edición con la sigla $O C I$ seguida de la página. 
dad, en la desolación del espíritu y en la falta de lo necesario se está firme e inmóvil (232).

En sus ensayos sobre mística, Valente menciona con frecuencia la retracción, proceso equivalente al exilio entendido como requisito indispensable de la actividad poética. A la manera de la negación mística, la creación exige prescindir de formas previas, requiere "retraerse" a la zona incondicionada del lenguaje. En la conferencia "Exilio y poesía" (1993), pronunciada en el marco del Coloquio Internacional sobre Los Poetas del Exilio Español en México, el poeta se refiere explícitamente a la continuidad entre el destino de Molinos y el de los últimos exilados españoles:

¿Es esta la materia de la historia? ¿La imagen del espíritu víctima de la hoguera o los exilios? ¿Serían los exilios una forma constante o necesaria de la historia misma, la negativa del espíritu a aceptar, cualesquiera que sean sus formas, toda no libertad que quieran imponerle la fuerza o el poder? (OCII, 680).

Lo que en términos de creación poética se traduce de esta manera:

El acto creador supone un movimiento exílico, una retracción, una distancia y, en la praxis humana, una retirada de los honores y, ciertamente, del territorio impuro del poder.

Lo primero - o acaso lo único- que crea el creador es el espacio vacío, desnudo, donde puede ser posible la creación. La creación es, en su primer y más esencial momento, no la creación de algo, sino la creación de nada (OCII, 683). ${ }^{14}$

Se trata, en última instancia, de prescindir de la identidad dada para adentrarse en un mundo incierto, lo cual recuerda el estribillo del primer poema que Valente dedica a san Juan de la Cruz, y que no llega a recoger en libro: "¿quién es el que camina hacia la noche / de confín a

${ }^{14}$ Esta idea encuentra perfecta realización en "Pabellón del vacío", último poema de Lezama Lima al que, por cierto, Valente dedica un ensayo incluido en La experiencia abisal (2004). Cfr. OCII, 673-677. 
confín, de río a río, / de frontera a frontera arrebatado?" (OCI, 785). ${ }^{15}$ Ese ir hacia la nada es patrimonio tanto del poeta como del místico cuando se enfrascan en la búsqueda de una palabra depurada del compulsivo deseo de control que regula las instituciones, ensombrece las relaciones interpersonales, y contamina el lenguaje.

Con la pregunta “¿quién es el que camina hacia la noche?” Valente marca la arriesgada inmersión de san Juan de la Cruz en las tinieblas, el desplazamiento continuo conseguido a través de la aniquilación.

Vale la pena recordar, a modo de reconocimiento, el papel que juega Calvert Casey en el encuentro de Valente con la Guía; gracias a este amigo cubano, se percata de los nexos entre formas de la mística oriental con experiencias que Occidente ha relegado, como es el caso de la enseñanza de Molinos. Juntos emprenden la lectura y comentario en común de la Guía, de los que surge la idea de preparar, con el mayor cuidado, una nueva edición de esta obra. Situados uno frente al otro, iluminándose mutuamente, Molinos y Casey representan para Valente la hazaña de la libertad, gracias a la cual la conciencia se extiende hasta tocar lo ilimitado:

Mi amigo cubano vivió o bebió con una intensidad sin tregua el texto de [la Guía], ese breve libro extraordinario, y en particular sus últimos cuatro capítulos. En ellos el canto a la aniquilación y a la nada [...] es uno de los más bellos ejemplos de irrupción radical de la prosa castellana en el espacio de la palabra poética. Al terminar el camino, todas las palabras son una; los ritmos se unifican. Queda, al cabo, el dibujo escueto y luminoso que Molinos trazó [...] de la "fábrica de la aniquilación", de la "oficina de la nada", del "aposento de la transparencia" (OCII, 731).

Como ya anticipé, la reflexión de María Zambrano sobre la "Guía", entendida como modalidad de pensamiento que se expresa literariamente, depende de la pregunta por una razón que supere el racionalismo europeo. En efecto, al inicio de su primer artículo sobre el tema, titulado " $\mathrm{La}$

${ }^{15}$ Como señala el editor de $O C I$, el poema "El desvelado" data de 1952. 
'Guía', forma del pensamiento" (1943), ${ }^{16}$ contrapone la Guía a la exposición sistemática que se ha impuesto en la filosofía, del mismo modo que la razón científico-tecnológica ha triunfado sobre el pensamiento capaz de incluir al individuo. Parte aquí del análisis de la Guía de perplejos de Maimónides. De forma complementaria, y en un movimiento típico de Zambrano, en esto tan discípula de Ortega, muestra la relación entre el auge moderno de la razón y el olvido europeo de España, donde se han cultivado los llamados géneros "menores", como la Guía misma, la Epístola y el Diálogo, entre otros. Así, en España la razón ha conseguido sustraerse al afán filosófico de universalizar. Desde esta óptica, Molinos, inesperadamente, pasa a formar parte de la estirpe de autores que se han arriesgado a enfrentar la violencia del sistema:

No solamente hay una vida que no se deja arrebatar al cielo de la objetividad sino que reacciona ante ella. Es Tomás de Kempis respondiendo a Tomás de Aquino; Epicteto a Aristóteles; Kierkegaard, desesperando a Hegel. Es la desnudez del hombre, su esencia irreducible, que clama por ellos (Zambrano, Confesiones y Guías, 114).

En estas reacciones se reconoce, como añade Zambrano, una aguda conciencia del tiempo, son respuesta al carácter inabarcable de la vida, a la imposibilidad de unificarla. En su limitación, por así decirlo, la vida requiere de la verdad que aporta la experiencia, se ajusta a una verdad apenas susurrada que invita al cambio: "la experiencia no es sino el conocimiento que no ha querido ser objetivamente universal por no dejar al tiempo solo. Por eso no puede tomar la forma enunciativa, por eso nunca será declaración completa" (115).

Lo anterior arroja luz acerca de la estructura de la Guía espiritual, obra que consta de un "Proemio" y tres "Libros". Los libros, que vendrían a ser secciones, están compuestos de "Capítulos", más bien breves, que a su vez se dividen en puntos. Así Molinos evita el desarrollo, la argumentación exhaustiva, incluso la cavilación; la unidad no depende tanto del hilo conductor, aunque el tema del capítulo queda enunciado al inicio, sino del arranque y pausa de un pensamiento que se

${ }^{16}$ En Confesiones y Guias, 103-124. Se incluye como capítulo en Un saber acerca del alma (1950). 
va condensando en párrafos cortos que hoy llamaríamos "fragmentos". Lejos de aportar demostraciones, las citas, más bien escasas, encajan en el tono y ritmo de la prosa. El estilo se ajusta al poderoso impulso comunicativo de la experiencia que habla al oído del otro con la intención de animarlo, no de convencerlo con razones. Esta flexibilidad incide en la aproximación al libro. La Guía de Molinos puede leerse linealmente, a modo de un discurso unitario, pero también se presta a la lectura desordenada, pues los puntos se sostienen con independencia, a manera de la sentencia o del aforismo. ${ }^{17}$ A estos "ritmos" expositivo y aforístico, Valente añade un tercero: el ritmo poético, "que responde a la trasposición de la experiencia y marca sobre el libro III o es el ritmo único de sus capítulos finales" ("Ensayo sobre Miguel de Molinos", 50).

En la reseña de la edición de la Guía de Valente, Zambrano ve la adecuación del "Ensayo sobre Miguel de Molinos" con el estilo fragmentario de Molinos. En lugar de invadir con explicaciones, el poeta va rodeando los asuntos, y da sugerencias. Pretende mostrar, no dilucidar. Este "comportamiento" es la respuesta certera a la experiencia que se condensa en el libro. Además, y esto es quizá lo más importante, la exposición de Valente reproduce el vaivén de la vida, su "desorden, el modo en que irrumpen los acontecimientos en la biografía de Molinos y en la realidad en general". ${ }^{18}$ Ronda aquí la marca del exilio en Zambrano, la sucesión precipitada de eventos por los que, de pronto, se encuentra fuera de su mundo, desprotegida de modo irremediable. Comparte así el destino de Molinos, al que se refiere como "ese español desamparado". De forma similar a Valente, la filósofa presenta a Molinos como emblema de una serie de "inocentes" que han sufrido la presión de la

${ }^{17}$ La proximidad con el pensamiento breve y de corte ético queda clara en el título del Capítulo XI del Libro tercero de la Guía: "Máximas para conocer el corazón sencillo, humilde y verdadero".

18 Víctima de las intrigas en Roma, a donde se había trasladado en 1663, el 18 de julio de 1685 el místico es apresado. Tras dos años de proceso, en septiembre de 1687, los días 2 y 13 respectivamente, se firma la sentencia y tiene lugar la abjuración en la basílica de Santa Maria sopra Minerva. Finalmente, en noviembre del mismo año aparecen las 68 proposiciones que contienen sus supuestos errores doctrinales. Después de haber obtenido gran prestigio como predicador y director espiritual, y a pesar de la popularidad de su libro, se confina a Molinos a la cárcel y al silencio. 
historia. El mérito del "Prólogo" de Valente consiste en reflejar, desde la estructura, el peso y el "enigma" que marcan la vida del místico:

Sin duda alguna, la visibilidad que este ensayo ofrece del conflicto histórico desencadenado en torno al inerme español Miguel de Molinos, y de la suerte y destino de la mística misma, se debe a una cierta modalidad de la luz que en el ensayo se extiende sin desfallecimiento. Es la claridad una modalidad de la luz en la que el hacer visibles las cosas y los seres predomina. [...] el enigma queda, en cuanto tal, visible ("Miguel de Molinos, reaparecido", 162).

La estructura flexible de la Guía, a la que responde el "Prólogo" de la edición de Valente, procede también de la experiencia. Interesante para el lector actual, en la Guía destaca la oposición entre la experiencia, piedra de toque de la mística, y el discurso, dominio del yo. Por ello, a través de la primera se accede a la contemplación.

Esta radical apuesta por la experiencia enlaza con las ideas de Zambrano acerca de la Guía en tanto que género literario, al que pertenecen incluso libros como "Vida de don Quijote y Sancho" de Unamuno. Con independencia del título, la "Guía" se caracteriza por estar dirigida a un público formado por "indecisos" o "perplejos", y por provenir de un conocimiento práctico. La afinidad con la mística se considera una expresión de la particularidad española, de la "extrañeza" histórica de este país. En este orden de ideas, Zambrano opone la Guía al sistema, esquema intelectual propio del racionalismo europeo. A diferencia de las pretensiones de saber sistemático, la guía orienta acerca de la "forma" adecuada para el cumplimiento de la vida, que es siempre única y por tanto irreducible a generalidades.

Dentro de una cultura rica, continúa Zambrano, se cuenta con un conjunto de posibilidades que son suficientes para que la mayoría de los individuos alcancen una forma, un carácter. A esto se llama tradición, que lejos de reducirse a un material estático requiere ser actualizado: se ejerce nuevamente en la vida particular. Sin embargo, este repertorio de posibilidades resulta insuficiente para algunas personas. Se trata de los "perplejos" a los que se dirigen las guías. Esta indecisión depende del ánimo: 
La perplejidad es una debilidad del ánimo que no proviene del conocimiento sino de la relación entre el conocimiento y el resto de la vida, que queda impermeable a él. Perplejo indica más bien sobrado de conocimiento. [...] Y es que a la muchedumbre de los acontecimientos se ofrece el hermetismo de su ánimo. $Y$ aunque conscientemente busca una resolución se defiende en realidad de encontrarla ("La 'Guía', forma del pensamiento", 123).

Al igual que la "vocación" en Ortega, la "forma" en Zambrano remite a la estética, y no sólo a la moral. Por ello, la forma es más una sugerencia, una aparición fugaz. Incluso puede decirse que a través de la experiencia no se trasmite un contenido determinado, sólo se modifica el talante o ánimo. Esto equivale a salir de la postración o el estancamiento. Las "guías" procuran animar, lo que se produce cuando el perplejo avizora una forma posible. Aquí es donde entran las advertencias de Molinos en relación con los directores espirituales que, por no haber atravesado ese camino, aplacan el ímpetu de los que son llamados a un camino "interior" (Molinos, Guía espiritual, 137). Sólo a partir de la experiencia se puede movilizar al perplejo:

Estos doctos meramente escolásticos, no saben qué cosa sea espíritu ni perderse en Dios ni han llegado a gustar las suaves ambrosías en el fondo íntimo del alma, donde está su trono y se comunica con increíble, íntima y regalada afluencia. Antes bien, algunos, sin entender esta ciencia (porque nadie la entiende sino el que la gusta), la condenan, y su parecer es seguido, aplaudido y venerado por la falta de luz que hay en el mundo y sobra de ceguedad (239; cursivas mías).

Molinos previene a los confusos acerca de las desviaciones más comunes en el camino a la "contemplación". De ahí el rechazo a las lecturas o clases, a la tendencia a sustituir la actividad por la que se cambia el ser, que está fuera del alcance de la razón, por tareas intelectuales. ${ }^{19}$

19 "Es cierto que la lección frecuente de los libros místicos que no se funda en luz práctica, sino en pura especulativa, hace más mal que bien, porque confunde a las almas en vez de alumbrarlas, y las llena de noticias discursivas que embarazan sumamente, porque aunque son noticias de luz, entran por fuera y embotan las potencias en vez de vaciarlas para que Dios las llene de sí mismo" (Guía, 139). 
Más que instrucción, se necesita ponerse en juego, precisamente para lo que faltan fuerzas al perplejo. ${ }^{20}$

Queda así descrita, sumariamente, la función que Zambrano atribuye a la Guía, y también el lugar principal que ésta ocupa en la historia española que, a diferencia de la del resto de Europa, se distinguiría por la atención que presta a las exigencias de desarrollo particulares, a la vida en su ejercicio. Así como para Valente el lenguaje de Molinos es modelo de austeridad que, en contraste con el boato del Barroco, establece la pauta de la mejor poesía española, para Zambrano este místico es un antecedente del pensamiento que se vuelca en la enseñanza, al estilo de Unamuno y Ortega.

Las sugerentes propuestas de Zambrano en torno a géneros menores, la Confesión y la Guía en concreto, dependen entonces de la revaloración de la experiencia, de la que se sigue una forma de filosofar "medicinal" que permite engarzar, en una unidad no forzada, el curso de la vida. No basta con tomar distancia e intentar objetivar los sucesos. Es necesario un impulso que, de alguna manera, se anticipe a la multiplicidad de los eventos. Y es aquí donde interviene otra forma de razón, una capaz de actuar en el plano simbólico, donde el hombre se reconoce a través de imágenes. A este plano apunta asimismo la idea orteguiana, retomada por Zambrano, acerca de descubrir el personaje de la "novela" que cada uno protagoniza. Sin esta acción imaginativa - la filósofa se refiere a ella como "estética"-, no se alcanza la unidad.

Con lo dicho, se entiende la función de las imágenes y los mitos como inspiración para imaginar la propia vida. Al final de su estudio sobre la Guía, se refiere a la imagen como "figura" que en esta clase de libros se muestra al perplejo, al lector sumido en la duda acerca de sí mismo. Se trata de una imagen que conmueve, que toca el "corazón". El amor se añade así, como aspecto nuevo, a la imagen. Para tener la fuerza suficiente el modelo o idea que se propone debe enamorar, inspirar al modo platónico, pero en este caso no se dirige a un universo ideal: la imagen impulsa en el plano práctico, mueve a transformar la vida. No deja de

20 Zambrano describe una situación semejante a lo que actualmente conocemos como depresión. El "perplejo" no encaja, no se reconoce en las posibilidades disponibles en su ambiente, ni goza de la independencia de los privilegiados que disponen de un "daimon" que les marca el camino. 
ser intrigante este último giro del ensayo: ¿cómo constituir una imagen individual que produzca amor? ¿Hacia dónde se dirige el que se oriente por esta "figura"? ¿Se trata del yo trascendido a la manera del "sí mismo" de Jung? La misma Zambrano expresa su asombro acerca del camino que se debe seguir para lograr esta "animación", ya que se trata, en última instancia, de un renacimiento: "Habrá mucho de arte, mucho de secreto personal, no reducible a generalizaciones. Cada autor de una Guía tendrá su manera propia, su personal hechizo. Tan sólo se puede señalar la acción que ejecutan [...]: hacer salir a la vida de sí, hacerla aceptar una visión de sí misma" ("La 'Guía', forma del pensamiento", 124).

En el límite del estudio, Zambrano no se apresura a dar explicaciones; al contrario, admite una última cualidad que escapa al análisis y que depende del propio talento, como ella señala al referir al "arte", el "secreto personal" y el "personal hechizo". Aparte del arte de la persuasión, el secreto se encuentra, como ella misma muestra, en la realidad y calidad de la experiencia transmitida que, en el caso de Molinos, se expresa en la prosa diáfana, incuestionable, de la Guía.

\section{REFERENCIAS}

Dodin, André, Diccionario de las religiones, Barcelona, Herder, 1987.

Molinos, Miguel de, Guía espiritual. Defensa de la contemplación, José Ángel Valente (ed.), Barcelona, Barral, 1974.

PACHо, Eulogio, La defensa de la contemplación, Madrid, Fundación Universitaria Española / Universidad Pontificia de Salamanca, 1988.

Ribas, Albert, "La mística heterodoxa de Miguel de Molinos", El Ciervo. Revista de pensamiento y de cultura, año 45, núm. 549, diciembre 1996, 27$30<\mathrm{http} / / /$ www.editorialsunya.com/molinos.html $>$ [1/03/2014].

Rojas, Rafael, "Calvert Casey. Herido por la luz", Letras Libres, 133, enero 2010, 50.

Valente, José Ángel, "Ensayo sobre Miguel de Molinos", en Miguel de Molinos, Guía espiritual. Defensa de la contemplación, Barcelona, Barral, 1974.

Valente, José Ángel, Obras Completas I. Poesía y prosa, edición e introducción de Andrés Sánchez Robayna, Barcelona, Galaxia Gutenberg / Círculo de Lectores, 2006.

Valente, José Ángel, "Teresa 'in capella Cornaro", en Obras Completas II. La piedra y el centro., ed. de Andrés Sánchez Robayna, recopilación e 
introducción de Claudio Rodríguez Fer, Barcelona, Galaxia Gutenberg, Círculo de Lectores, 2008, 296-300.

Zambrano, María "Miguel de Molinos reaparecido" [1975], en Confesiones y Guías, edición, introducción y notas de Pedro Chacón, Madrid, Eutelequia, 2011.

Zambrano, María, "La 'Guía', forma del pensamiento", en Confesiones y Guías, edición, introducción y notas de Pedro Chacón, Madrid, Eutelequia, 2011. 